\title{
PENGARUH PEMBELAJARAN INTEGRATIVE LEARNING (IL) DAN PREDICT, DISCUS, EXPLAIN, OBSERVE, DISCUSS (PDEODE) TERHADAP PEMAHAMAN KONSEP
}

\author{
Ardian Asyhari ${ }^{1}$, Dina Hariyanti ${ }^{2}$ \\ ${ }^{12}$ Program Studi Pendidikan Fisika, FTK UIN Raden Intan Lampung \\ Email: ardianasyhari@radenintan.ac.id
}

\begin{abstract}
This study aims to determine the understanding of physics concepts in physical quantities and their measurement. This research is a Quasi Design Experiment. The population in this study was the entire class X. The study was conducted at Tegineneng 1 Public High School in 2018/2019, using two classes, namely class X MIPA 1 as the experimental class I using learning and learning PDEODE class X MIPA 2 as the experimental class II. The sampling technique is done by purposive sampling technique. The instrument used in this study was a four-tier diagnostic test for understanding concepts and LKPD as a support for the implementation of the learning model. Data analysis using SPSS 23.0. For data analysis using the normality test, homogeneity test, and Anava two ways to test the hypothesis against posttest data. Based on the results of research that has been done shows that understanding the concept of experiment 1 with IL learning model is (63.7), and for experimental class 2 with PDEODE that is equal to (65.28) and for the first hypothesis testing is $(0.93>0,05)$ H_OA is accepted meaning that there is no influence on the use of Integrative Learning and Predict, Discus, Explain, Observe, Discuss, Explain (PDEODE) learning which is $0.00<0.05 \mathrm{H}_{-} 0 \mathrm{~B}$ is rejected, it means there is an influence on understanding the concepts of high and low physics. The third one gets $0.75>0.05 \mathrm{H} \_0 \mathrm{~A} * \mathrm{~B}$ accepted, it means that there is no interaction between learning Integrative Learning and Predict, Discus, Explain, Observe, Discuss, Explain (PDEODE) on understanding the concept, because the two learning models are equally good to be applied into learning of the two experimental classes ...
\end{abstract}

Keywords: Concept Understanding , Discus , Discuss , Explain, Explain (PDEODE), Integrative Learning (IL) And Predict, Observe

\begin{abstract}
ABSTRAK
Penelitian ini bertujuan untuk mengetahui pemahaman konsep fisika pada materi besaran fisika dan pengukurannya. Penelitian ini merupakan Quasi Eksperimen Design. Populasi dalam penelitian ini adalah seluruh kelas X. Penelitian dilakukan di SMAN 1 Tegineneng tahun pelajaran 2018/2019, menggunakan dua kelas, yaitu kelas X MIPA 1 sebagai kelas eksperimen I dengan menggunakan pembelajaran dan pembelajaran PDEODE kelas X MIPA 2 sebagai kelas eksperimen II. Teknik pengambilan sampel dilakukan dengan teknik purposive sampling. Instrumen yang digunakan dalam penelitian ini berupa tes berupa soal pilihan jamak beralasan (four tier diagnostic test) untuk pemahaman konsep dan LKPD sebagai pendukung untuk keterlaksanaan model pembelajaran. Analisis data menggunakan SPSS 23.0. Untuk analisa data menggunakan uji normalitas, uji homogenitas, dan Anava dua jalan untuk menguji hipotesisnya terhadap data posttest. Berdasarkan hasil penelitian yang telah dilakukan menunjukkan bahwa pemahaman konsep eksperimen 1 dengan model pembelajaran IL yaitu $(63,7)$, dan untuk kelas eksperimen 2 dengan PDEODE yaitu sebesar $(65,28)$ dan untuk uji hipotesisnya yang pertama adalah $(0,93>0,05) H_{0}$ A diterima artinya tidak ada pengaruh penggunaan pembelajaran Integrative Learning dan Predict, Discus, Explain, Observe, Discuss, Explain (PDEODE) yang kedua yaitu $0.00<0.05 H_{0} \mathrm{~B}$ ditolak artinya ada pengaruh pada pemahaman konsep tinggi dan rendah fisika. Yang ketiga memperoleh 0,75>0,05 $\mathrm{H}_{0} \mathrm{~A} * \mathrm{~B}$ diterima artinya tidak interaksi antara pembelajaran Integrative Learning dan Predict, Discus, Explain, Observe, Discuss, Explain (PDEODE) terhadap pemahaman konsep, karena kedua model pembelajaran tersebut sama baiknya untuk diterapkan kedalam pembelajaran kedua kelas eksperimen tersebut.
\end{abstract}

* Copyright (c) 2020 Ardian Asyhari dan Dina Hariyanti

This work is licensed under a Creative Commons Attribution-ShareAlike 4.0 International License. 
Khazanah Pendidikan Islam, Vol. 2 No. 1: 43-52

Pengaruh Pembelajaran Integrative Learning (Il) Dan Predict, Discus, Explain, Observe, Discuss

(Pdeode) Terhadap Pemahaman Konsep

Ardian Asyhari dan Dina Hariyanti

Kata Kunci: Amati , Discus, Discuss, Explain, Explain (PDEODE), Integrative Learning (IL) Dan Predict,

Pemahaman Konsep.

\section{PENDAHULUAN}

Pendidikan merupakan bagian penting bagi kehidupan yang dapat memberi perbedaan bagi manusia dengan makhluk hidup lainnya atau usaha-usaha sadar manusia tertata dan terencana dengan suatu perencanaan yang matang agar mempunyai perubahan pada dirinya untuk mempunyai kualitas yang baik, baik dari perilaku, sikap, keterampilan yang dibutuhkan oleh dirinya, masyarakat, bangsa dan negara. Agar terciptanya cita-cita dengan cara mengembangkan potensi-potensi kegiatan manusia secara bertahap. Dalam mewujudkan suasana belajar dan proses pembelajaran tersebut maka manusia itu sendiri harus mencapainya dengan usaha-usaha yang disengaja dan berencana. Agar sasaran dari perubahannya dapat sesuai dengan yang diinginkan (Chairul Anwar, 2017; Ihsan H. Fuad ,2008; Nurani Soyomukti; 2016; Imam Macali Didin Mizan, 2012; Mega Utami Pertiwi Damanhuri dkk, 2017; Ardimen, 2016). Undang-undang Republik Indonesia No 20. Tahun 2003 tentang sistem Pendidikan Nasional, menjelaskan bahwa pendidikan adalah usaha sadar dan terencana untuk mewujudkan suasana belajar dan proses pembelajaran agar mengembangkan potensi dirinya untuk mengembangkan kekuatan spiritual, keagamaan, pengendalian diri, kepribadian, kecerdasan, akhlak mulia, serta keterampilan yang diperlukan dirinya, masyarakat, bangsa, agama dan negara sebagai generasi penerus yang akan mendatang. (Suryadi Asep Suryana, 2019).

Fisika ialah salah satu bagian sains yang berkaitan dengan kehidupan sehari-hari yang mempelajari benda-benda di alam secara fisik fenomena dan gejala alam semesta. Dengan seluruh interaksi yang terjadi di dalamnya. Untuk gejala fenomena alam, fisika biasanya dituangkan menggunakan persamaan (angka), konsep yang sedikit dan prinsip hukum yang teruji kebenarannya secara ilmiah.( A. Suhandi dan F C Wibowo, 2012; M Nor and Revi Astria Noprina, 2013; Sudi Dul Aji and Muhammad Nur Hudha, 2017; Hadma Yuliani, 2017). Pembelajaran fisika juga bukan hanyalah pada pengetahuan fakta-fakta di kehidupan tetapi juga penghafalan rumus atau bagian dari ilmu sains yang perlu dilengkapi dengan memahami konsep abstrak yang mendasar dan bisa dimulai dari diri seorang pendidik dengan memberikan pengajaran yang lebih mudah dipahami, dimengerti oleh seorang pendidik. (Idham Kholid, Antomi Saregar dan Anis Marlina, 2017; Sadam Husein et al,2015; Yuberti , Rahma Diani dan Shella Syafitri, 2016). Kebanyakan sekolah di Indonesia yang menggunakan kurikulum K13. Kurikulum K13 harus relevan dengan kebutuhan manusia. Dalam K13 diharapkan mampu menunjang kualitas pendidikan Indonesia sebab di dalam K13 terdapat beberapa prinsip pembelajaran seperti, prinsip K13 yaitu mendorong peserta didiknya lebih aktif dari pada gurunya.( Agus Wahyuni, Cut Eka Parasamya, 2017; Afni Lindra, 2013). Pembelajaran yang efektif itu artinya peserta didik dapat mengembangkan dan memperluas perubahan konsepsi ke arah konsepsi yang benar dengan begitu membantu peserta didik dalam menguasai konsep baru. Guru dalam pembelajaran yang efektif memberi kebebasan untuk dapat belajar mengamati, mencari konsep dan pemecahan masalah dalam suatu pembelajaran tertentu termasuk fisika ini secara mandiri. (Sutopo Muhammad Nur Hudha, Lia Yuliati, 2016; M P Restami et al, 2013).

Hasil dari wawancara dan observasi langsung guru mata pelajaran fisika kelas X khususnya pada kelas X MIPA 1 dan X MIPA 2 dengan melihat aktivitas saat proses pembelajaran berlangsung di SMAN 1 Tegineneng tahun ajaran 2018/2019, ditemukan beberapa permasalahan yaitu menunjukkan bahwa masih rendah pemahaman konsep peserta didiknya, peserta didik cenderung pasif dan belum 
Khazanah Pendidikan Islam, Vol. 2 No. 1: 43-52

Pengaruh Pembelajaran Integrative Learning (Il) Dan Predict, Discus, Explain, Observe, Discuss

(Pdeode) Terhadap Pemahaman Konsep

Ardian Asyhari dan Dina Hariyanti

sepenuhnya memahami konsep fisika walaupun sudah dikaitkan dengan kehidupan sehari-hari oleh guru . Terlihat saat hasil belajar peserta didik nilainya masih di bawah KKM. Sebab saat proses pembelajaran berlangsung peserta didik sulit untuk menerima penjelasan guru, karena menurut peserta didik pelajaran fisika itu sulit dan menurut peserta didik fisika banyak rumus sehingga bingung harus memakai rumus yang mana untuk menyelesaikan masalah fisika dan pada pembelajaran fisika guru masih menggunakan model pembelajaran yang belum kontekstual masih lebih sering teacher center, mencatat dipapan tulis serta memberikan latihan soal tanpa adanya variasi-variasi model pembelajaran lainnya. Penerapan model pembelajaran dengan teacher center belum cukup sepenuhnya berhasil karena tingkat pemahaman konsep merupakan kunci untuk mengerti fisika. Sering ditemukan fenomena di kehidupan sehari-hari. Kenyataannya peserta didik masih kurang menyadari bahwa fenomena fisika yang terjadi di kehidupan nyata. Oleh karena itu, peserta didik kurang paham pentingnya materi fisika untuk kehidupan nyata. Di dalam pengajaran sebaiknya guru menghubungkan dengan dunia nyata agar peserta didik dilatih untuk menjelaskan fenomena fisika dengan pendekatan saintis. Kenyataannya memahami materi fisika harus dikaitkan konsep materi sebelumnya. (Lia Yuliati dan Nandang Mufti Lis Suswati,2015) Rendahnya hasil belajar peserta didik di SMAN 1 Tegineneng, Kecamatan Negeri Katon, Kabupaten Pesawaran, disebabkan oleh peserta didik yang kurang memahami tentang pembelajaran Fisika sebab guru masih sering menggunakan teacher center dalam proses pembelajaran. Sebaiknya sudah terjadi perubahan dalam proses pembelajaran dari teacher center menuju student center. Melihat permasalahan di atas, maka dalam penelitian ini model pembelajaran yang lain perlu diujicobaan utuk mengatasi permasalahan tersebut. Oleh karena itu peneliti memilih Integrative Learning dan Predict, Discus, Explain, Observe, Discuss, Explain (PDEODE) sebagai model yang dipilih untuk meningkatkan pemahaman konsep peserta didik.

\section{METODE PENELITIAN}

Metode yang digunakan adalah Quasi eksperimen . Desain penelitian yang digunakan Posttest only Control Group Design. Adapun rancangan penelitian yang digunakan dalam penelitian ini adalah desain faktorial $2 \times 2$. Populasi yang digunakan dalam penelitian ini adalah seluruh peserta didik kelas X MIPA di SMAN 1 Tegineneng. Sampel yang digunakan kelas X MIPA 1dan 2 sebagai kelas eksperimen keduanya. Penentuan sampel dilakukan menggunakan purposive sampling. Instrumen yang digunakan yaitu soal posttest pilihan jamak beralasan (four tier diagnostic) untuk mengetahui pemahaman konsep peserta didik. Materi yang diujikan dikelompokkan menjadi 6 indikator pembelajaran menjelaskan besaran dan satuan, menyebutkan macam-macam besaran okok dan turunan, membaca nilai yang ditunjukkan alat ukur, menentukan suatu dimensi suatu besaran, menganalisis besan pokok dan turunan dalam kehidupan sehari-hari dan mengoperasikan angka penting.

\section{Model Pembelajaran}

Model pembelajaran merupakan bentuk pembelajaran yang tergambar dari awal sampai akhir yang disajikan secara khas oleh guru. Model pembelajaran terdapat 4 (empat) kelompok model pembelajaran yaitu: a. Model interaksi sosial, b. Model pengolahan informasi c. Model peronalhumanistik, d. Model modifikasi tingkah laku. Dengan demikian, sering kali penggunaan istilah model pembelajaran tersebut diidentikkan dengan strategi pembelajaran. Berlin Sani Imas Kurniasih, 2007).

\section{Integrative Learning}

Model Integrative Learning menurut Ritland terdiri dari; Informed Exploration, Enactment, Evaluation Local Impact, dan Evaluation Broader Impact (Brenda Bannan-Ritland, 2003). Keterampilan 
Khazanah Pendidikan Islam, Vol. 2 No. 1: 43-52

Pengaruh Pembelajaran Integrative Learning (Il) Dan Predict, Discus, Explain, Observe, Discuss

(Pdeode) Terhadap Pemahaman Konsep

Ardian Asyhari dan Dina Hariyanti

secara terpadu dapat dioptimalkan melalui scientific approach yang terdiri dari mengamati, menanya, mengumpulkan informasi, mengasosiasi, dan menyimpulkan. Oleh karena itu, peserta didik lebih mendalam untuk memahami konsep-konsep fisika. Konsep-konsep fisika dapat ditanamkan salah satunya melalui model Integrative Learning. Pada model pembelajaran tersebut, peserta didik dilatih untuk mengembangkan keterampilan berpikir kritis sekaligus kemampuan pemecahan masalah. Shi menyatakan bahwa Integrative Learning dapat menguatkan pengetahuan secara mendalam berdasarkan pengalaman langsung yang ditempuh selama proses pendidikan. (Agus Suyudi,Anifatul Azizah, Lia Yuliati, 2016). Langkah-langkah pembelajaran integrative learning adalah Pendidik memutarkan video atau gambar tentang materi yang sedang dipelajari a. Pendidik meminta peserta didik membentuk kelompok untuk merumuskan masalah berdasarkan video atau gambar yang ditayangkan. b.Pendidik meminta peserta didik untuk menganalisis data secara berulang-ulang dan menyimpulkan data berdasarkan hasil diskusi. c. Pendidik meminta peserta didik untuk mengaplikasikan konsep ke dalam kehidupan nyata untuk mengembangkan pemahamannya. Kegiatan akhir yaitu Pendidik memberikan tugas rumah untuk memperdalam materi pembelajaran. (Agus Suyudi ,Anifatul Azizah, Lia Yuliati, 2016). Kelebihan pembelajaran dengan integrative learning terlihat dari fase pembelajaran yang terakhir, yaitu fase broad evaluation. Tahapan ini memberikan kesempatan kepada siswa untuk berpikir liberal (bebas). (Lia Yuliati dan Nandang Mufti Lis Suswati, 2015).

\section{Model Predict, Discus, Explain, Observe, Discuss, Explain (PDEODE)}

Model pembelajaran Predict, Discus, Explain, Observe, Discuss, Explain (PDEODE) merupakan pengembangan dan modifikasi dari model pembelajaran POE (Predict-Discuss-Explain). Model pembelajaran ini merupakan model yang penting sebab memiliki atmosfer yang dapat menunjang diskusi dan keragaman cara pandang. Oleh karena itu model ini bermaksud digunakan untuk membantu peserta didik memaknai terhadap pengalaman kehidupannya sehari-hari. (Eli Yustika, 2018). Model pembelajaran PDEODE dapat menciptakan iklim pembelajaran yang kondusif sesuai dengan keterampilan proses sains. Menurut Mansoor Niaz dalam jurnal yang berjudul Investigating the effectiveness of a POE-based teachinh activity on students understanding of condensation, bahwa pembelajaran PDEODE sebagai sarana dalam menyelusuri pemahaman peserta didik tentang suatu konsep ilmu (Raden Raisa Wulandari dan Fauzi Bakri, 2015). Guru disini sebagai motivator dan fasilitator yang membimbing, mengarahkan, serta membantu peserta didik agar dapat berinteraksi dengan lingkungan dan kehidupan sehari-hari. Peserta didik dalam menyelesaikan suatu masalah menggunakan percobaan dalam penyelesaiannya sesuai dengan perkembangan kognitif. Model pembelajaran PDEODE memiliki enam tahapan menurut Costu, yaitu a. Tahap memperediksi (Prediction) Peserta didik diberikan oleh guru suatu fenomena sains atau permasalahan terkait materi yang akan dibahas, Peserta didik secara individu meramalkan (memprediksi) dan memberikan alasan berdasarkan pengetahuan awal yang dimiliki peserta didik. b. Tahap Diskusi (Discuss) Peserta didik secara berkelompok mendiskusikan jawaban dan penjelasan atas fenomena atau permasalahan yang telah mereka prediksi. c. Tahap menjelaskan I (Explain I) Masing-masing kelompok menyampaikan hasil diskusi, setelah memperoleh alasan dari prediksi yang telah dibuat. d. Tahap Observasi (Observe) Perbedaan pendapat yang terjadi saat diskusi tidak dibiarkan berlarut-larut yang selanjutnya melalui kegiatan observasi dilakukan dengan percobaan-percobaan yang berkaitan dengan fenomena tersebut. e. Tahap Diskusi II (Discuss II) Peserta didik bersama kelompok melanjutkan diskusi kedua untuk merumuskan kembali dan membandingkan berdasarkan hasil observasi antara hipotesis awal dengan setelah selesai pengamatan atau praktikum. f. Tahap menjelaskan II (Explain II) Pada Tahap ini, peserta didik menjelaskan terkait jawaban atas permasalahan yang ada secara detail dengan argumentasi yang logis dari penjelasan yang terbukti kebenaran terkait permasalahan yang diberikan. Selain itu PDEODE dapat membantu peserta didik dalam membangun konsep-konsep yang ilmiah karena peserta didik dapat berpikir mandiri, berdiskusi dalam 
Khazanah Pendidikan Islam, Vol. 2 No. 1: 43-52

Pengaruh Pembelajaran Integrative Learning (Il) Dan Predict, Discus, Explain, Observe, Discuss

(Pdeode) Terhadap Pemahaman Konsep

Ardian Asyhari dan Dina Hariyanti

kelompok, melakukan pengamatan dalam percobaan secara langsung, membandingkan prakonsep peserta didik dengan hasil percobaan sehingga menemukan konsep baru yang ilmiah. (Farizzatul Erza and Harun Nasrudin, 2017) Kelebihan yang dimiliki model pembelajaran PDEODE yaitu peserta didik aktif dalam proses pembelajaran, mengonstruksi secara mandiri pengetahuan dari fenomena yang ada, membuat motivasi dan kreativitas belajar peserta didik tinggi, menggali gagasan awal yang dimiliki peserta didik dan membangkitkan rasa ingin tahu serta diskusi antar peserta didik maupun dengan guru dan kelemahan yaitu dalam pembelajaran membutuhkan alokasi waktu yang cukup banyak sehingga materipelajaran terkadang sulit disampaikan secara tuntas, serta peserta didik yang belum terbiasa dalam menyelesaikan permasalahan dengan pengamatan sehingga kurang merasa percaya diri. ( $\mathrm{Nym} \mathrm{Sdarmi,} \mathrm{Ni}$ Kt Suarni, and I Kt Dibia, 2013).

\section{Pemahaman Konsep}

Konsep merupakan hal yang sangat penting untuk dikuasai dalam proses pembelajaran. Santrock (2001) menyatakan bahwa konsep dapat membantu peserta didik menyederhanakan, meringkas, dan mengatur informasi yang diterima. Penguasaan konsep, khususnya konsep IPA penting bagi peserta didik untuk memperoleh dan mengombinasikan pengetahuan yang dimiliki. Selain itu, dapat membantu peserta didik dalam menyelesaikan suatu permasalahan yang ada dalam kejadian sehari-hari. (Sugeng Utaya and Lia Yuliati, 2017). Menurut Bloom mengemukakan bahwa yang dimaksud dengan pemahaman adalah kemampuan menangkap pengertian-pengertian seperti mampu mengungkapkan suatu materi yang disajikan dalam bentuk lain yang dapat dipahami, mampu memberikan interpretasi dan mampu mengklasifikasikannya. Indikator pemahaman konsep menurut Benyamin S. Bloom adalah Penerjemahan (translation) yaitu menerjemahkan konsepsi abstrak menjadi suatu model. Misalnya dari lambang ke arti. Kata kerja operasional yang digunakan adalah menerjemahkan, mengubah, mengilustrasikan, memberikan definisi, dan menjelaskan kembali. Penafsiran (interpretation) yaitu menerjemahkan konsepsi abstrak menjadi suatu model. Misalnya dari lambang ke arti. Kata kerja operasional yang digunakan adalah menerjemahkan, mengubah, mengilustrasikan, memberikan definisi, dan menjelaskan kembali. Ekstrapolasi (extrapolation) sebagai berikut: yaitu menyimpulkan dari sesuatu yang telah diketahui. Kata kerja operasional yang dapat digunakan untuk mengukur kemampuan ini adalah memperhitungkan, menduga, menyimpulkan, meramalkan, membedakan, menentukan dan mengisi. Dalam tes objektif, tipe pilihan ganda dan tipe benar-salah banyak mengungkapkan aspek pemahaman.( Nana Sudjana, 2012).

\section{Tes Diagnosis Four-Tier}

Tes diagnostik merupakan salah satu instrumen untuk mendeteksi miskonsepsi dengan mengetahui kelemahan serta kekuatan peserta didik pada pelajaran tertentu. ( Fitri Nurul, Achmad Samsudin, and Muhamad Gina, 2017). Diagnostik pemahaman konsep melalui Four Tier Test merupakan pengembangan instrumen Three Tier Test. Tes diagnostik pilihan ganda empat tingkat dirancang untuk menentukan seberapa kuat peserta didik menguasai konsep melalui tingkat keyakinan dalam menjawab pertanyaan. (Dini Frihanderi Aprita, Bambang Supriadi, and Trapsilo Prihandono, 2018). (Four-Tier Diagnostic Test atau tes diagnostik pilihan ganda empat tingkat yang dikembangkan dalam penelitian ini menghasilkan instrumen tes yang berfungsi untuk mengungkap pemahaman konsep peserta didik pada materi besaran fisika dan pengukurannya. 
Khazanah Pendidikan Islam, Vol. 2 No. 1: 43-52

Pengaruh Pembelajaran Integrative Learning (Il) Dan Predict, Discus, Explain, Observe, Discuss

(Pdeode) Terhadap Pemahaman Konsep

Ardian Asyhari dan Dina Hariyanti

\section{HASIL DAN PEMBAHASAN}

Hasil dari penelitian ini yang pertama adalah pemahaman konsep fisika peserta didik setelah diterapkan model pembelajaran Integrative Learning (IL) dan Predict, Discus, Explain, Observe, Discuss, Explain (PDEODE), disajikan pada tabel 1.

Tabel 1. Rekapitulasi Indikator pemahaman konsep eksperimen 1 dan eksperimen 2.

\begin{tabular}{|c|l|l|l|}
\hline $\begin{array}{l}\text { Indikator } \\
\text { pemahaman } \\
\text { konsep }\end{array}$ & $\begin{array}{l}\text { No } \\
\text { soal }\end{array}$ & \multicolumn{2}{|l|}{$\begin{array}{l}\text { Rata-rata } \\
\text { presentase } \\
\text { pemahaman } \\
\text { konsep }\end{array}$} \\
\cline { 3 - 4 } & & Eks=1 & Eks = 2 \\
\hline Penerjemah & $\begin{array}{l}8,12, \\
13,14\end{array}$ & $\begin{array}{l}64,40 \\
\%\end{array}$ & $73 \%$ \\
\hline Penafsiran & $\begin{array}{l}1,2,3, \\
6,7,9,\end{array}$ & $\begin{array}{l}66,41 \\
\%\end{array}$ & $61 \%$ \\
\hline Ekstrap & 15,16 & & \\
\hline olasi & $4,10,1$ & $9 \%$ & $\%$ \\
& $1,17,18$ & & 6 \\
\hline
\end{tabular}

Pada tabel diatas dapat dilihat bahwa pada setiap indikator antara kelas eksperimen 1 (IL) dan kelas eksperimen 2 (PDEODE) rata-rata persentasenya lebih besar kelas eksperimen 2 (PDEODE).

\section{Pengujian Hipotesis}

Pada pengujian hipotesis dilakukan pengujian prasyarat analisis dengan uji normalitas Kolmogiorov-Smirnov.

Tabel 2. test of normality

\begin{tabular}{|ll|c|c|c|}
\hline \multirow{2}{*}{} & & \multicolumn{3}{|c|}{$\begin{array}{c}\text { Kolmogorov- } \\
\text { Smirnova }\end{array}$} \\
\cline { 3 - 5 } MODEL & & $\begin{array}{c}\text { Stati } \\
\text { stic }\end{array}$ & df & Sig. \\
\hline PRESENTA & PEMBELAJAR & & & \\
SE_PK & AN & & & \\
& INTEGRATIV &, 156 & 18 &, $200^{*}$ \\
& E LEARNING & & & \\
& & & & \\
& PEMBELAJAR & & & \\
& AN PDEODE &, 147 & 18 &, $200^{*}$ \\
& & & & \\
\hline
\end{tabular}


Khazanah Pendidikan Islam, Vol. 2 No. 1: 43-52

Pengaruh Pembelajaran Integrative Learning (Il) Dan Predict, Discus, Explain, Observe, Discuss

(Pdeode) Terhadap Pemahaman Konsep

Ardian Asyhari dan Dina Hariyanti

Hasilnya menunjukkan bahwa nilai-nilai statistik pada variabel IL (kelas eksperimen 1) yang diperoleh memiliki angka signifikansi 0,200>0,05. Pada variabel PDEODE (kelas eksperimen 2). Diperoleh nilai sebesar signifikansi $0,200>0,05$. Hal ini berarti bahwa data pemahaman konsep fisika peserta didik berdistribusi normal.

Tabel 3. Test of Homogeneity of Variances

PRESENTASE_PK

\begin{tabular}{|r|r|r|r|}
\hline $\begin{array}{c}\text { Levene } \\
\text { Statistic }\end{array}$ & df1 & \multicolumn{1}{c|}{ df2 } & Sig. \\
\hline, 149 & 1 & 34 &, 702 \\
\hline
\end{tabular}

Pengujian homogenitas varian menggunakan Levene's Test untuk pemahaman konsep fisika dan sikap ilmiah siswa menunjukkan angka-angka signifikansi statistik Levene sig 0,702>0,05. Hal ini menunjukkan bahwa varian pemahaman konsep fisika peserta didik adalah homogen.

Setelah data diketahui terdistribusi normal dan homogen maka dilanjutkan dengan uji hipotesis ANAVA dua jalan. Selanjutnya data dianalisis secara deskriptif dan dengan menggunakan ANAVA faktorial 2x2. Semua pengujian hipotesis dilakukan dengan taraf signifikansi 5\% dengan menggunakan SPSS 23.

Tabel 4. Tests of Between-Subjects Effects

\begin{tabular}{|l|r|rr|}
\hline & \multicolumn{1}{|c|}{ F } & \multicolumn{1}{c|}{ Sig. } \\
\hline MODELC (A) &, 008 & &, 93 \\
PK (B) & 69,43 &, 00 \\
MODEL * PK (A*B) &, 284 &, 755 \\
\hline
\end{tabular}

Berdasarkan analisis memperoleh hasil sebagai berikut. Pertama terhadap pemahaman konsep didapatkan nilai signifikan 0,93 karena nilai signifikan >0,05 sehingga $H_{0}$ A diterima dan $H_{1}$ A ditolak atau tidak ada pengaruh pembelajaran Integrative Learning dan Predict, Discus, Explain, Observe, Discuss, Explain (PDEODE). Hal tersebut menunjukan keseimbangan antara model pembelajaran Integrative Learning dan Predict, Discus, Explain, Observe, Discuss, Explain (PDEODE). Hipotesis kedua hasil pemahaman konsep memperoleh nilai signifikan sebesar $0,00<0,05$ sehingga $H_{0} \mathrm{~B}$ ditolak dan $H_{1} \mathrm{~B}$ diterima atau terdapat pengaruh pemahaman konsep. Hipotesis ke tiga hasil uji pemahaman konsep yang ditinjau dari hubungan antara penggunaan pembelajaran dan pemahaman konsep peserta didik memperoleh nilai signifikan sebesar 0,75>0,05 sehingga $H_{0} \mathrm{~A}^{*} \mathrm{~B}$ diterima dan $H_{1} \mathrm{~A}^{*} \mathrm{~B}$ ditolak atau tidak ada iteraksi antara pembelajaran Integrative Learning dan Predict, Discus, Explain, Observe, Discuss, Explain (PDEODE) dalam menentukan pemahaman konsep peserta didik pada pembelajaran fisika.

\section{Pembahasan}

Penelitian ini dilakukan oleh 2 kelas eksperimen dengan menggunakan model pembelajaran Integrative Learning dan Predict, Discus, Explain, Observe, Discuss, Explain (PDEODE) yang digunakan ternyata memberikan bukti hipotesis yang ada. Pada uji hipotesis pertama ini berdasarkan analisa data hasil penelitian adalah tentang pengaruh model pembelajaran Integrative Learning dan Predict, Discus, Explain, Observe, Discuss, Explain (PDEODE) terhadaap kemampuan konsep tinggi dan rendah, kemudian kita bisa melihat pada tabel 4.8 tentang anava test menunjukkan dengan taraf signifikan sebesar 0,93 > $0,05 H_{0} \mathrm{~A}$ diterima menunjukan bahwa tidak terdapat pengaruh yang signifikan pada kedua model 
Khazanah Pendidikan Islam, Vol. 2 No. 1: 43-52

Pengaruh Pembelajaran Integrative Learning (Il) Dan Predict, Discus, Explain, Observe, Discuss

(Pdeode) Terhadap Pemahaman Konsep

Ardian Asyhari dan Dina Hariyanti

pembelajaran tersebut. Hal ini berarti bahwa seimbang antara model pembelajaran Integrative Learning dan Predict, Discus, Explain, Observe, Discuss, Explain (PDEODE).

Pada rata-rata Persentase pemahaman konsep peserta didik dengan menggunakan model pembelajaran Integrative Learning sebesar 63,37 sedangkan model pembelajaran Predict, Discus, Explain, Observe, Discuss, Explain (PDEODE) memperoleh nilai sebesar 65,28 ini berarti bahwa persentase ratarata kelas dengan menggunakan kedua model tersebut Integrative Learning dan Predict, Discus, Explain, Observe, Discuss, Explain (PDEODE) sama baiknya atau seimbang, tetapi jika dilihat dengan persentase pemahaman konsep yang lebih besar menggunakan model pembelajaran PDEODE, Sama dengan penelitian yang dilakukan oleh (Bismillah Ali dam Amiruddin Kade, 2015; Raden Raisa Wulandari and Fauzi Bakri, 2015;). dikarenakan keunggulannya dari Pembelajaran PDEODE ini pada penelitian di lapangan pembelajaran ini menggunakan observasi dengan lembar praktikum jadi memahami konsepnya lebih mendalam sebab peserta didik akan mengerti konsep dengan pengalaman langsung, sedangkan dengan pembelajaran integrative learning peserta didik memahami konsep materi yang sedang berlangsung dengan mengintegrasikan pengetahuan konsep hanya dengan mengaplikasikannya kedalam kehidupan sehari-hari sebab peserta didik akan lebih sulit apabila hanya mengetahui konsep tertulis tanpa mengetahui bagaimana praktiknya di kehidupan sehari-hari walaupun Pada model pembelajaran integrative learning ini peserta didik yang tadinya pasif menjadi aktif dalam proses pembelajaran di kelas tetapi untuk lebih mendalami konsep yang mendalam tidak hanya melihat pada contoh kehidupan seharihari tetapi dengan praktik langsung.

Berdasarkan hasil analisa data penelitian hipotesis diterima berarti menunjukkan terdapat pengaruh tingkat pemahaman konsep dapat dilihat pada tabel 4.8 anava test menunjukkan bahwa nilai yang diperoleh $0,00<0,05$. Dapat disimpulkan bahwa $H_{0} \mathrm{~B}$ ditolak dan $H_{1} \mathrm{~B}$ diterima. Hal tersebut karena pemahaman konsep menjadi perhatian dalam proses pembelajara di kelas, pentingnya pemahaman konsep adalah agar peserta didik memilik kemampuan memahami konsep dan mengaplikasikan pengetahuan untuk kehidupan nyata dengan memperhatikan lingkungan. (Lis Suswati, 2015)

Dari perhitungan anava dua jalan uji hipotesis ketiga yaitu tentang interaksi antara model pembelajaran dan pemahaman konsep peserta didik . pada penelitian ini peneliti menggunakan model pembelajaran Integrative Learning dan Predict, Discus, Explain, Observe, Discuss, Explain (PDEODE). Sedangkan untuk pemahaman konsep dikelompokkan menjadi dua kategori yaitu dengan pemahaman konsep tinggi dan rendah. Apabila nilai signifikan $<0,05$ maka penelitiannya terdapat interaksi. Pada tabel 4.8 memperoleh data senilai 0,755 $>0,05$ maka disimpulkan bahwa $H_{0} \mathrm{AB}$ diterima yang artinya tidak terdapat interaksi antara model pembelajaran terhadap pemahaman konsep. Berdasarkan teori tersebut peserta didik yang mempunyai kemampuan pemahaman konsep tinggi akan lebih mudah belajar dengan menggunakan model pembelajaran Integrative Learning dan Predict, Discus, Explain, Observe, Discuss, Explain (PDEODE) dengan begitu pemahaman konsep akan baik juga, sedangkan yang memiliki pemahaman konsep yang rendah akan cukup sulit memahami konsep dan nilai hasil belajarnya juga akan mendapatkan nilai yang rendah juga.

Penggunaan model IL dan PDEODE tidak memberi pengaruh yang signifikan terhadap pemahaman konsep peserta didik. Tidak sesuaian ini dengan hasil penelitian yang sebelumnya ada dikarenakan terdapat beberapa faktor yang mempengaruhinya. Penelitian yang dilakukan Lis dkk menyimpulkan terdapat pengaruh IL yang signifikan. (lis Suswanti 2016). Dan menurut Tismi dkk bahwa terdapat interaksi pada model PDEODE. (Tismi Dipalaya etal,2016). Pada peserta didikyang memiliki pemahaman konsep yang rendah tidak menutup kemungkinan memiliki kemampuan paham konsep yang baik setelah model pembelajaran diterapkan. Walaupun begitu ada yang pemahaman konsep tinggi dan rendah 
Khazanah Pendidikan Islam, Vol. 2 No. 1: 43-52

Pengaruh Pembelajaran Integrative Learning (Il) Dan Predict, Discus, Explain, Observe, Discuss

(Pdeode) Terhadap Pemahaman Konsep

Ardian Asyhari dan Dina Hariyanti

keduanya mampu mengikuti proses pembelajaran dengan baik pada model pembelajaran yang telah diterapkan, semua tergantung kepada perilaku masing-masing peserta didik dalam proses pembelajaran di kelas.

\section{SIMPULAN}

Secara kesimpulannya adalah metodelogi penafsiran yang digunakan di dalam Al-Qur'an adalah untuk menjelaskan apa yang terdapat di dalam Al-Qur'an dengan mudah. Ini karena Al-Qur'an itu bersifat global dan perlu di perjelaskan dengan menggunakan ilmu yang ada. Untuk itu, da'I juga harus mengetahui supaya tidak berlaku kesalahfahaman dalam menjelaskan kepada masyarakat. Dengan memperhatikan hasil penelitian, kesimpulan yang telah didapat, peneliti memberikan beberapa saran sebagai berikut:

Pendidik menerapkan model pembelajaran Integrative Learning dan Predict, Discus, Explain, Observe, Discuss (PDEODE) agar dapat meningkatkan kemampuan pemahaman konsep yang baik dan Perlu diadakan penelitian lebih lanjut mengenai model pembelajaran Integrative Learning dan Predict, Discus, Explain, Observe, Discuss, Explain (PDEODE) dengan materi berbeda dan sampel kelas yang berbeda khususnya pada materi fisika mungkin dapat ditambah dengan variabel terikat lainnya selain pemahaman konsep.

\section{DAFTAR PUSTAKA}

A. Suhandi dan F C Wibowo. (2012). Pendekatan Multirepresentasi Dalam Pembelajaran UsahaEnergi Dan Dampak Terhadap Pemahaman 8.

Agus ,Anifatul Azizah, Lia Yuliati. (2016). Pengaruh Model Integrative Learning Terhadap Kemampuan Pemecahan Masalah Fisika Siswa Kelas X SMA Laboratorium UM Pada Materi Fluida Statis. Jurnal Pendidikan Sains.

Agus Wahyuni, Cut Eka Parasamya. (2017). Upaya Peningkatan Hasil Belajar Fisika Siswa Melalui Penerapan Model Pembelajaran Problem Based Learning (Pbl). Jurnal Ilmiah Mahasiswa (JIM) Pendidikan Fisika. 2.

Anwar, Chairul. (2014). Hakikat Manusia Dalam Pendidikan. UIN Sunan Kali Jaga Yogyakarta: SUKA-Press.

- - , (2008). Teori-Teori Pendidikan Klasik Hingga Kontemporer (Yogyakarta: IRCiSod, 2017). h.73; dilihat juga Ihsan H. Fuad, Dasar-Dasar kependidikan. Jakarta: PT Rineka Cipta.

Ardimen. (2016). Pengembangan Multiple Intelligence Melalui Pembelajaran Integratif Berbasis Games. Jurnal Edukasi 2.

Bannan-Ritland, Brenda. (2003). The Role of Design in Research: The Integrative Learning Design Framework (Educational Researcher: (Online) (www.eric.ed).

Idham Kholid, Antomi Saregar dan Anis Marlina (2017). Efektivitas Model Pembelajaran Arias Ditinjau Dari Sikap Ilmiah: Dampak Terhadap Pemahaman Konsep Fluida Statis. Jurnal Ilmiah Pendidikan Fisika Al-BiRuNi 6, no. 2. https://doi.org/10.24042/jipfalbiruni.v6i2.2181.

Lindra, Afni. (2013). Pembelajaran Contextual Teaching And Learning (Ctl) Di Dalam Kurikulum.

Lindra, Hadma. (2017). Pembelajaran Fisika Menggunakan Media Animasi Macromedia Flash-Mx Dan Gambar. Jurnal Ilmiah Pendidikan Fisika Al-BiRuNi 6, no. April, https://doi.org/10.24042/jpifalbiruni.v6i.

Machali, Imam. (2016). islam memandang hak asasi pendidikan. Jurnal pendidikan islam vol.27.no.1.

Machali, Imam dan Didin Kumjadin, (2013). Manajemen Pendidikan Konsep \& Prinsip Pengeloa Laan Pendidikan. Bandung: Mizan. 


\section{Khazanah Pendidikan Islam, Vol. 2 No. 1: 43-52}

Pengaruh Pembelajaran Integrative Learning (Il) Dan Predict, Discus, Explain, Observe, Discuss

(Pdeode) Terhadap Pemahaman Konsep Ardian Asyhari dan Dina Hariyanti

Mega Utami Pratiwi Damanhuri, Zerri Rahman Hakim. (2017). Penerapan Model Pembelajaran Inquiri Terhadap Hasil Belajar Siswa Sekolah Dasar Pada Mata Pelajaran Ips Universitas Sultan Ageng Tirtayasa A . Pendahuluan Mata Pelajaran I, JPSD 2.

Nor, M, And Revi Astria Noprina. (2013). Penerapan Pendekatan Arias Pada Siswa Kelas Viii Smp Negeri 4 Tambang. Prosiding Semirata Fmipa Universitas Lampung.

Sani, Berlin dan Imas Kurniasih. (2017). Lebih Memahami Konsep \& Proses Pembelajaran. Jakarta: Kata Pena.

Suhardi Nurul Mu'minin. (2016). Pengembangan Perangkat Pembelajaran Tematik-Integratif Berbasis Sastra Bagi Siswa Kelas V Sekolah Dasar, Jurnal Prima Edukasia 4, no. 2: 176-85".

Sutopo Muhammad, Nur Hudha, Lia Yuliati. (2016). Perubahan Konseptual Fisika Dengan Authentic Problem Melalui Integrative Learning Pada Topik Gerak Lurus Pada Sma Suryabuana Malang. Jurnal Inspirasi Pendidikan Universitas Kanjuruhan Malang 6.

Suryadi Asep Suryana. (2009). Pengelolaan Pendidikan. Jakarta: Departemen Agama Republik Indonesia.

Soyomukti, Nurani. (2016). Teori-Teori Pendidikan. Yogyakarta: Ar-Ruzz Media.

Yuliati, Lia dan Nandang Mufti Lis Suswati. (2015). Pengaruh Integrative Learning Terhadap Kemampuan Berpikir Kritis Dan Penguasaan Konsep Fisika Siswa. Jurnal Pendidikan Sains 3.

Yustika, Eli. (2018). Pengembangan Modul Praktikum Teleskop Reflektor Berbasis Model Pdeode. Pendidikan Fisika 6. 